\title{
Models for Living: 1905 - 2005
}

\section{A survey of 100 years of New Zealand Residential Architecture. An exhibition presented at the Auckland War Memorial Museum} 8 April - 19 June 2005

\author{
Review I by Peter Bartlett
}

The exhibition, in celebration of the centenary of the NZIA, comprised fifty scale-model houses designed by architects and delicately crafted by students-all pure white in paper and card. They represented a selection of New Zealand domestic architectural designs whose scope ranged from 1905 to 2005. The exhibition was supported by video projections of David Mitchell's "The Elegant Shed" and the Hamish Keith/Bill Saunders documentary "The City and the Suburbs".

Not surprisingly, since model making is daunting, the representative house selection is a thin one. Presumably, the range of models will be augmented for future exhibition elsewhere. Modeling of this precision is irresistible both to gaze and hand, captivatingly tantalizing, and more so here when protected from grasp. Yet while each model on its abrupt white pedestal exalts and focuses, it is also deprived of any evidence of external elements important to the design's genesis. The visual triggering available, and the perception that follows, are derived from a finite architectural object without context, rather than from any interaction with an environment. Our own mental stock of notional environments may compensate a bit, but only roughly so.

What these exquisitely detached models of detached houses preclude is our perceptual grasp of the often specific and crucial design influences and living experiences that lie beyond these mostly suburban dwelling exteriors in the wider spaces of site and landscape. Nor can we convincingly comprehend interiors as indicators of designed ways-of-life, or as influences on exterior form. Though one can revel in the often voluminous living spaces, one can hardly do so at all in the variety of plan arrangements, which remain unrevealed in the models. Thus, one design seriously 


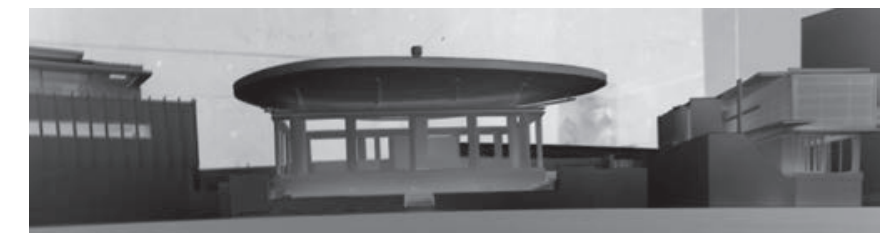

ROJECT:

OCATION:

RCHITECT:

BRICK BAY GUEST HOUSE WARKWORTH

NOEL LANE ARCHITECTS

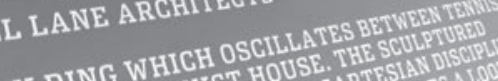

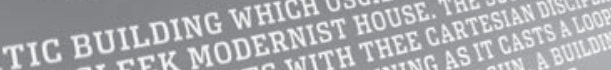

SNIGMATIC BUEEK MODTS WITH THER ASIT CWS BUU

AN ENIGN AND SLENTRASTS WORLANNERNOON SW WI

PAVILION ROOF CON INTERTOR THE AETRTOFIND

GRADLED RLLS AND NET IN TISITOR TWTHOH

DF THEW OVER TENGES THE REDIT

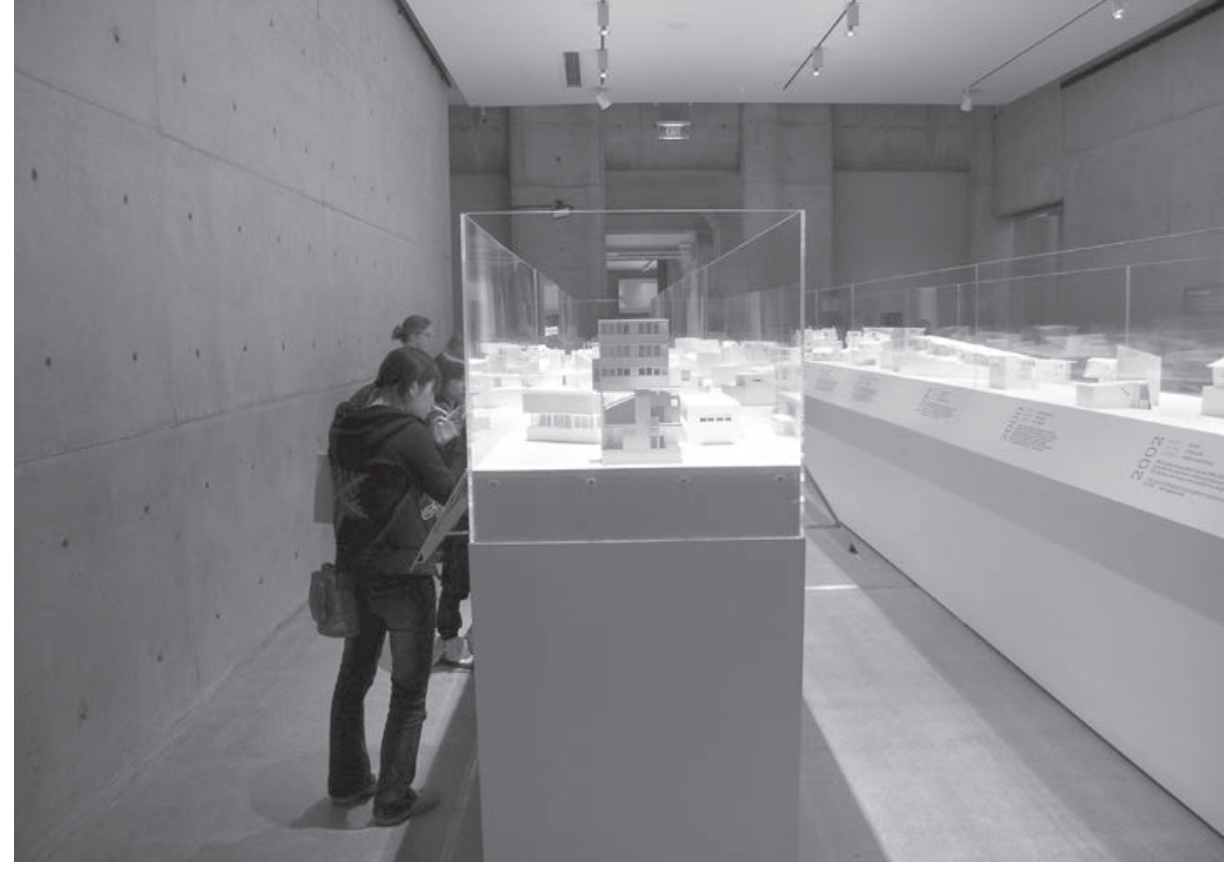

Figures I and 2: The model display in the 'concrete gallery'. Photos Tim Adams.

misrepresented is Mike Austin's Chapple house-one struggles to recognize the house without its pohutukawa pivot and its black lava brink. More satisfying, however, is the exception: Andrew Patterson's Summer Street courtyard house, where site-is-house-is-model. Plans and site plans would have enabled this fuller comprehension in other cases, as too might have the alternative medium of digital and photographic modeling, with the added advantages of permitting a much increased range of house samples, as well as a means of readily reproducing them all.

The similarities and differences of external form are most discernible across the range, being uncomplicated by pronounced material or colour cues. The stuttering evolution of suburban dwelling form and composition-its elaborations and reductions-is superbly highlighted for scrutiny.

The suburb has clearly scored as the main testing ground for creativity, even though, as the models demonstrate, at the end of the century architectural intrigue and merit are irresistibly wedded to wealth. Wealthdriven residential work that excels in keeping abreast or ahead of this testing tumult defies canonisers, mostly because of its inherent freedoms and non-conformity - at least until that work chooses to embrace the pangs of negative reinforcement which sustainability imperatives now confront it with.

Canon seeking amidst this turbulence is history's privilege and, increasingly, one which must compound and mediate international as well as local acts and readings of architecture. While canons to the (new) right seem illusory, canons to the left of us might have a chance. Low to middle income levels equate with conservative, slower-changing habits and more 
normalized tastes. Moreover, a prospect arises of eventually looking back on residential minor canons, about to be created under the stimuli and constraints of two intensifying challenges: sustainability, and the intensification of suburban nodes and arteries, the latter tending to an anti-suburban typology.

What this house show is about is the fixation of the creative edge and the resources of designers and their times. The ignition of engagement in any matrix of ideas, opportunities and constraints, by which an architect is motivated, is inevitably ephemeral. Thus, on reflection, two impressions suggest themselves: first, the fate of award-winning buildings is to become familiarized, type-cast, and diluted by commodification. Secondly, an inevitable benefit of this fate is to register, through their durability, memorials to their times. Domestic architecture leaves rich, tell-tale traces of swings in design and life aspirations. For future cultural epidemiologists, celebrated house designs, together with their 'trickle-down' hybrids in the community, will afford good litmus tests of wider social trends.

Whilst the worlds of the café, the restaurant, retail and recreation have known well how to draw upon stage settings and practices for their theatricality, their humanity, and certainly their farce, most urban office and institutional environments have evolved into places of comparative abstraction. These places bear little resemblance either to the former, or to the creative vitality of home places. Is this adequate, or not? Will it persist, or is likely that prolonged familiarity with such workplace minimalism, with abstraction a relentless conditioning basis, presumes a confident shift towards greater abstraction in future dwelling environments? 